\title{
Low doses of CMV induce autoimmune-mediated and inflammatory responses in bile duct epithelia of regulatory $\mathrm{T}$ cell-depleted neonatal mice
}

\author{
Jie Wen ${ }^{1,2,3,6}$, Yongtao Xiao 1,2,3,6, Jun Wang ${ }^{1}$, Weihua Pan ${ }^{1}$, Ying Zhou ${ }^{1}$, Xiaoling Zhang ${ }^{4}$, Wenbin Guan ${ }^{5}$,
} Yingwei Chen ${ }^{2,3}$, Kejun Zhou ${ }^{2,3}$, Yang Wang ${ }^{2,3}$, Bisheng Shi ${ }^{4}$, Xiaohui Zhou ${ }^{4}$, Zhenghong Yuan ${ }^{4}$ and Wei Cai ${ }^{1,2,3}$

Recent studies have indicated that perinatal infection with cytomegalovirus (CMV) may promote bile duct damage in biliary atresia (BA) and that the decreased regulatory $T$ cell (Treg) percentage associated with BA may further amplify the bile duct damage. Although a majority of BA patients have had previous CMV infections and lower percentages of Tregs, it is unknown whether an initial exposure to a low dose of CMV could induce exaggerated and progressive biliary injury. A Treg-depleted neonatal mouse was infected with low-dose CMV (LD-CMV) as a model to study BA patients. LD-CMV infection in Treg-depleted mice induced extensive inflammation in both the intrahepatic and extrahepatic bile ducts, accompanied with injury to and atresia of intrahepatic bile ducts and partial obstruction of the extrahepatic bile ducts. Serum total and direct bilirubin amounts were also elevated. Evidence for the involvement of cellular and humoral autoimmune responses in LD-CMV-infection of Treg-depleted mice was also obtained through detection of increased percentages of CD3 and CD8 mononuclear cells and serum autoantibodies reactive to bile duct epithelial proteins, one of which was identified as $\alpha$-enolase. Depletion of Tregs that can lead to the decreased inhibition of aberrantly activated hepatic T-lymphocytes and generation of autoantibodies may lead to further injury. Increased hepatic expression of Th1-related genes (TNF- $\alpha$ ), IFN- $\gamma$-activated genes (STAT-1) and Th1 cytokines (TNF- $\alpha$, lymphotactin, IL-12p40 and MIP $-1 \gamma$ ) were also identified. In conclusion, autoimmune-mediated and inflammatory responses induced by LD-CMV infection in Treg-depleted mice results in increased intrahepatic and extrahepatic bile duct injury and contributed to disease progression.

Laboratory Investigation (2015) 95, 180-192; doi:10.1038/labinvest.2014.148; published online 22 December 2014

Biliary atresia (BA) is a disease that is characterized by intrahepatic bile duct (IHBD) and extrahepatic bile duct (EHBD) inflammation, which leads to fibrosis and eventual bile duct obstruction. ${ }^{1-4}$ Because of the progressive nature of this disease, up to $80 \%$ of BA patients eventually require liver transplantation. $^{5-7}$ Furthermore, for reasons that are not clear, the disease continues to progress even after adequate bile flow is restored through a surgical Kasai portoenterostomy intervention.

The etiology and pathogenesis of BA are largely unknown. The coordinated activation of proinflammatory genes and the oligoclonal expansion of $\mathrm{T}$ cells in liver tissues of $\mathrm{BA}$ patients suggest that BA is an autoimmune-mediated disease. ${ }^{8,9}$ A leading theory regarding the pathogenesis of $\mathrm{BA}$ is that the bile duct damage is initiated by a viral infection. The viral infection induces an abnormal autoimmune response, which targets the bile duct and the autoimmune responses continue to persist even after the virus is cleared. ${ }^{9-14}$

Cytomegalovirus (CMV), a double-stranded DNA virus from the Herpesviridae family, is known to infect and injure bile duct epithelia. CMV inclusion bodies and/or CMV

\footnotetext{
'Department of Pediatric Surgery, Xin Hua Hospital, School of Medicine, Shanghai Jiao Tong University, Shanghai, China; ${ }^{2}$ Shanghai Key Laboratory of Pediatric Gastroenterology and Nutrition, Shanghai, China; ${ }^{3}$ Shanghai Institute for Pediatric Research, Shanghai, China; ${ }^{4}$ Key Lab of Medical Molecular Virology, Department of Pathogen Diagnosis and Biosafety, Shanghai Public Health Clinical Center, Fudan University, Shanghai, China and ${ }^{5}$ Department of Pathology, Xin Hua Hospital, School of Medicine, Shanghai Jiao Tong University, Shanghai, China

Correspondence: Dr Z Yuan, MD, PhD, Key Lab of Medical Molecular Virology, School of Basic Medical Science, Shanghai Medical College of Fudan University, Shanghai 200030, China or Dr W Cai, Department of Pediatric Surgery, Xin Hua Hospital, School of Medicine, Shanghai Jiao Tong University, or Shanghai Key Laboratory of Pediatric Gastroenterology and Nutrition, Shanghai 200092, China.

E-mail: zhyuan@shaphc.org or caiw1978@163.com

${ }^{6}$ These authors contributed equally to this work.

Received 26 May 2014; revised 21 September 2014; accepted 31 October 2014
} 
antigens have been found within the bile duct epithelia of BA patients. ${ }^{15-17}$ Recently, it was reported that $56 \%$ of BA patients had significantly higher liver T-cell numbers in response to CMV and that a positive correlation exists between plasma anti-CMV IgM and CMV-specific T cells in the liver of BA patients. ${ }^{17-21}$ Regulatory T cells (Tregs) are defined by expression of the surface markers CD4 and CD25 and the transcription factor Foxp3. ${ }^{22}$ Tregs represent a small percentage of $\mathrm{CD}_{4}^{+} \mathrm{T}$ cells and are indispensable for the maintenance of peripheral tolerance and the prevention of autoimmune diseases. ${ }^{23}$ Research has shown that patients with BA have a significantly lower frequency of peripheral blood Tregs compared with controls. Lower number of Tregs can promote inflammation and autoreactivity, potentially leading to further injury to the bile duct. ${ }^{24-26}$

It has been observed that in BA patients there is often no obvious sign of viral infection even though the disease continues to progress. Therefore we propose that infection of Treg-deficient individuals with a low dose of CMV, which is asymptomatic and unperceivable in normal infants, may induce a series of immune responses directed towards the bile ducts. These immune responses may potentially have a significant role in the pathogenesis and progression of BA.

To test this hypothesis, Treg-depleted neonatal mouse was infected with low-dose CMV (LD-CMV) to simulate BA patient. The aim of this study was to determine whether perinatal hepatobiliary exposure to low doses of CMV could trigger autoimmune-mediated and inflammatory responses, leading to bile duct injury in Treg-deficient neonatal mice. We found that LD-CMV infection in Treg-depleted mice led to extensive inflammation of intrahepatic bile duct and EHBDs, resulting in injury and atresia of intrahepatic bile ducts and partial obstruction of EHBDs. Total and direct bilirubin amounts were elevated in the blood. Furthermore, evidence for involvement of cellular and humoral autoimmune pathways was demonstrated by the activation of hepatic T-lymphocytes and the presence of serum autoantibodies that were reactive to bile duct epithelia. Hepatic expression of Th1-related genes (TNF- $\alpha$ ) and IFN- $\gamma$-activated genes (STAT-1), as well as Th1 cytokines (TNF- $\alpha$, lymphotactin, IL-12p40 and MIP $-1 \gamma$ ) were identified in this mouse model. This predominant hepatic expression of Th1-related genes and cytokines raised the possibility that the Th1 response resulted in the inflammatory and autoimmunemediated injury to the bile duct in this mouse model.

\section{MATERIALS AND METHODS Ethics Statement}

Animal experiments were carried out in strict accordance with the regulations in the Guidance Suggestions for the Care and Use of Laboratory Animals issued by the Ministry of Science and Technology of the People's Republic of China. The protocol was approved by the institutional Animal Care and Use Committee of the Xinhua Hospital Research Foundation (Permit Number: 2012-015).

\section{Animal Models}

The HCMV-AD169 strain (kindly provided by Institute Pasteur of Shanghai, Chinese Academy of Sciences) was maintained in MRC-5 cells (ATCC), which was a variant strain and has been reported to be able to infect mice, rats and rabbit. ${ }^{27-29}$ Timed-pregnant female BALB/c mice were purchased from the National Rodent Laboratory Animal Resources, Shanghai. At $24 \mathrm{~h}$ of birth, a low-dose concentration of CMV (LD-CMV, $5 \times 10^{4} \mathrm{PFU}$ ) or a high-dose concentration of CMV (HD-CMV, $1 \times 10^{6} \mathrm{PFU}$ ) in $15 \mu \mathrm{l}$ of saline or $15 \mu \mathrm{l} 0.9 \% \mathrm{NaCl}$ (saline control) was administered to Balb/c mice via intraperitoneal injection. All neonatal mice were maternally raised under specific pathogen-free conditions and were maintained on a 12-h dark-light cycle. CMVinjected and saline-injected mice litters were housed in separate cages to prevent dissemination of the virus. Pups were also injected $5 \mu \mathrm{g}$ of purified antibody every 3 days i.p. beginning on day 1 of life for 10 days, with a total of $20 \mu \mathrm{g}$ of purified anti-CD25 antibody (clone PC-61, rat IgG1; Biolegend, San Diego, CA, USA) or $20 \mu$ g isotype-matched IgG antibody. Mice were euthanized at different time points following CMV or saline injections, and the organs and blood were collected for analysis. Whole livers and spleens were isolated from separate groups of mice and were either snap frozen in liquid nitrogen or used for isolation of mononuclear cells.

\section{Histopathology and Immunohistochemical Analysis}

Neonatal mouse livers were harvested using a dissecting microscope. Tissues were snap frozen in liquid nitrogen, sectioned and stained with hematoxylin/eosin (H\&E) for microscopic analysis. For immunohistochemistry, cryostat sections were initially fixed with cold acetone. Endogenous peroxidases were removed by incubation with $0.3 \% \mathrm{H}_{2} \mathrm{O}_{2}$ for $15 \mathrm{~min}$ at room temperature (RT), and blocking was performed using $5 \%$ goat serum for $1 \mathrm{~h}$ at RT. Slides were incubated with an anti-CMV PP65 antibody (Boyan, Zhengjiang, China) diluted at 1:50 or anti- $\alpha$-SMA antibody (Sigma-Aldrich, MO, USA) diluted at 1:400 in 5\% bovine serum albumin overnight in a wet chamber. The slides were then rinsed in phosphate-buffered saline (PBS) and incubated with horseradish peroxidase-conjugated goat anti-rabbit or mouse IgG antibody (Cell Signaling, Danvers, MA, USA) (diluted at $1: 200)$ for $1 \mathrm{~h}$ at RT. Antibody binding was visualized using a liquid DAB Substrate Chromogen System (Dako, Glostrup, Denmark). The slides were rinsed in PBS and counterstained with hematoxylin. For immunofluorescence, anti-cytokeratin 7 antibody (KRT7, Proteintech) or anti-caspase 3 antibody (Cell Signaling) was used to identify bile duct epitheliae and apoptosis, respectively. Slides were treated overnight, in a wet chamber with rabbit anti-cytokeratin 7 IgG primary antibody diluted at 1:200 or rabbit anti-caspase 3 IgG primary antibody diluted at 1:50 in PBS. Slides were then rinsed in PBS and incubated with goat anti-rabbit IgG secondary antibody (KPL, Gaithersburg, MD, USA) for $1 \mathrm{~h}$ at RT. For the serum 
autoantibody studies, pooled sera from the treatment groups (dilution 1:20; $n=3$ each) was added to murine intrahepatic biliary epithelial cells (MIC-CELL-0076, PriCells, Wuhan, China) or to liver sections, collected from normal mice, followed by goat anti-mouse IgG secondary antibody (KPL). Slides or cells were counterstained with DAPI and visualized using the Nikon Eclipse Ti Inverted microscope. Digital photographs were obtained with a Nikon Digital Camera DXM 1200C, and identical exposure times were used for all samples.

\section{Real-Time PCR}

Total RNA was extracted from tissues with Trizol (Invitrogen, Carlsbad, CA, USA) according to the manufacturer's protocol. cDNA was synthesized using a High Capacity cDNA Reverse Transcription kit (Applied Biosystems, Foster City, CA, USA). SYBR-Green Universal Master Mix kit (Applied Biosystems) were used to analyze the relative mRNA amounts of different proteins. All reactions were repeated three times, and GAPDH was used to normalize the target genes. The following PCR primers were used: GAPDH, forward, $5^{\prime}$-TGG TTTGACAATGAATACGGCTAC-3' ${ }^{\prime}$, reverse, $5^{\prime}$-GGTGGGT GGTCCAAGGTTTC- $3^{\prime}$; Caspase-1, forward, 5'-CCTGGTCT TGTGACTTGGAGG-3', reverse, 5'-CTATCAGCAGTGGGCA TCTGTAG-3'; TNF- $\alpha$, forward, $5^{\prime}$-AAGGGAGAGTGGTCAG TTGCC- $3^{\prime}$, reverse, $5^{\prime}$-CCCAGGGAAGAGTCTGGAAAGG-3'; STAT-1, forward, 5'-CGAGTATTTGGGGCAAGGTGAG-3', reverse, 5'-GAAACATTCCTCCATCAAGAAGGC-3'; IL-13, forward, $5^{\prime}$-CCCTGGATTCCCTGACCAAC- $3^{\prime}$, reverse, $5^{\prime}$-CCA GGGATGGTCTCTCCTCA-3'; Gata-3, forward, 5'-GCTACGG TGCAG AGGTATCC-3' ${ }^{\prime}$, reverse, $5^{\prime}$-GCGGATAGGTGGTAAT GGGG-3'; IL-4, forward, 5'-CCACGGATGCGACAAAAATC-3', reverse, $5^{\prime}$-TGTTCTTCGTTGCTGTGAGGAC-3'; and IL-17a, forward, $5^{\prime}$-TCATCCCTCAAAGCTCAGCG-3' ${ }^{\prime}$, reverse, $5^{\prime}$-TT CATTGCGGTGGAGAGTCC-3'.

\section{Mouse Inflammation Array}

A mouse inflammation array kit was purchased from RayBiotech (Atlanta, GA, USA). Briefly, the membranes were blocked with a blocking buffer. Then $1 \mathrm{ml}$ of diluted liver lysate from mice in the LD-CMV + CD25 or Saline $+\operatorname{IgG}$ groups was added, and the membranes were incubated overnight at $4{ }^{\circ} \mathrm{C}$. The membranes were washed and then incubated with $1 \mathrm{ml}$ of primary biotin-conjugated antibody for $2 \mathrm{~h}$ at RT. The membranes were washed again and subsequently incubated with $2 \mathrm{ml}$ of horseradish peroxidase-conjugated streptavidin at RT for $2 \mathrm{~h}$. The signal was detected directly from the membrane using a chemiluminescence imaging system.

\section{Mononuclear Cell (MNC) Isolation and Flow Cytometric Analysis}

MNCs were isolated from the freshly harvested spleens and livers, passaged through a $40-\mu \mathrm{m}$ cell strainer, centrifuged and subjected to red cell lysis (BD Biosciences, San Diego, CA, USA). Cell staining for flow cytometry was conducted according to the manufacturer's instructions. Briefly, cells were surface stained by incubation with fluorochrome-conjugated $\mathrm{mAbs}$ for $10 \mathrm{~min}$, in the dark, at $4{ }^{\circ} \mathrm{C}$. The following antibodies were used: APC-CD3, PE-CD8, FITC-CD4 and PE-CD25 (Miltenyi Biotech, Auburn, CA, USA). Intracellular staining with APC-Foxp3 (eBiosciences, San Diego, CA, USA) was performed following surface staining and treatment with fixation/permeabilization buffer (eBioscience) according to the manufacturer's instructions. Background fluorescence was evaluated by staining the cells at optimal concentrations with isotype control antibodies. Cells were then analyzed using a FACSAriaII (BD Biosciences), with excitation at 488 and $633 \mathrm{~nm}$. Data were analyzed using FlowJo (Tree Star, Stanford, USA).

\section{Western Blotting Analysis}

Western blotting analysis was performed using standard procedures. Protein sources for the western blotting analyses included murine intrahepatic biliary epithelial cells (MICCELL-0076, PriCells, Wuhan, China; $2 \mathrm{mg} / \mathrm{ml}$ ) and purified rabbit muscle enolase (Sigma-Aldrich; high isoform homology with $\alpha$-enolase)..$^{30,31}$ Proteins were loaded onto a NuPAGE $10 \%$ Bis-Tris gel (Invitrogen) and run at $80 \mathrm{mV}$ for $3 \mathrm{~h}$. A full-range Rainbow recombinant molecular weight marker was placed in an adjacent lane. The proteins were transferred onto a $0.2-\mu \mathrm{m}$ nitrocellulose membrane using a dry blotting system (iBLOT system, Invitrogen), and the membranes were blocked in PBS with 5\% nonfat milk at RT for 60 min. Pooled sera from different treatment groups were diluted (1:100) in the milk blocking solution and incubated with the proteincontaining membrane overnight at $4{ }^{\circ} \mathrm{C}$. The membranes were washed three times with PBS and $0.1 \%$ Tween-20 and then incubated with goat-anti-mouse IgG-peroxidase (Cell Signaling). After final washes with PBS and $0.1 \%$ Tween-20, the signals were detected using ECL chemiluminescence reagents (Pierce, Rockford, IL, USA). Western blotting analysis was repeated three times in separate experiments.

\section{Statistical Analysis}

All data are expressed as mean \pm s.d. Data are evaluated by $T$-test or one-way ANOVA for multiple comparisons using the SPSS19 software program. $P$-values of $<0.05$ are considered statistically significant.

\section{RESULTS}

LD-CMV Inoculated Neonatal Mice Experienced Growth Retardation after Tregs Depletion

Newborn BALB/c pups were inoculated intraperitoneally with $5 \times 10^{4} \mathrm{PFU}$ of CMV (LD-CMV), or $1 \times 10^{6} \mathrm{PFU}$ of CMV (HD-CMV) as positive control, on day 1 of age. Based on previous findings in both BA patients and animal models, ${ }^{19,25}$ Tregs were depleted by injecting neonatal mouse with $20 \mu \mathrm{g} /$ mice anti-CD25 antibody or $20 \mu \mathrm{g} /$ mice isotype-matched IgG antibody (injection schedule is shown in Figure 1a). Anti-CD25 antibody injection significantly 
a

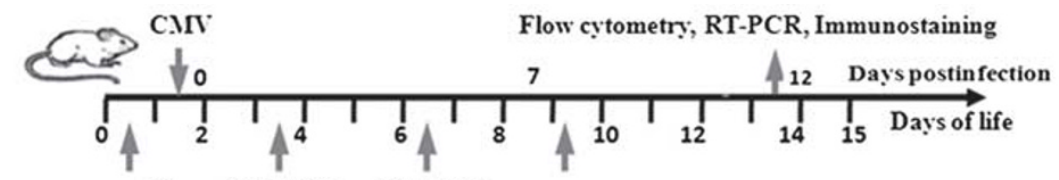

$20 \mu \mathrm{g}$ of CD25 (clone PC 61); i.p.

$20 \mu \mathrm{g}$ of Rat-IgGl in controls; i.p.

b

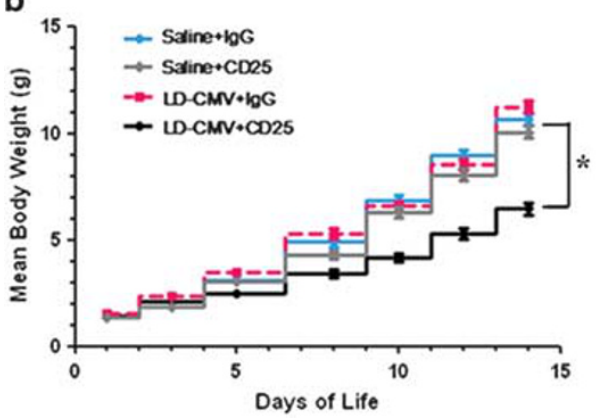

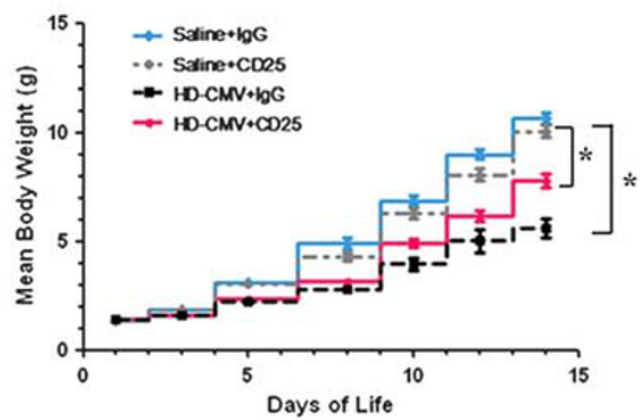

Figure 1 Effect of LD-CMV and HD-CMV infection on body weight gain in Treg-depleted neonatal mice. (a) Newborn BALB/c pups were inoculated intraperitoneally with $5 \times 10^{4}$ PFU of CMV (LD-CMV) or $1 \times 10^{6}$ PFU of CMV (HD-CMV) on day 1 of life. Pups were also treated with a total of $20 \mu \mathrm{g}$ CD25 antibody or $20 \mu \mathrm{g}$ isotype-matched IgG antibody within 2 weeks. (b) Average body weight gain from different groups. The body weight of LD-CMV + CD25 mice was significantly lower than that of other groups at 12 days post-CMV injection $\left({ }^{*} P<0.05\right.$, ANOVA). HD-CMV + IgG and $\mathrm{HD}-\mathrm{CMV}+\mathrm{CD} 25$ mice also showed severe growth retardation after virus inoculation, with body weight that were significantly lower than that of the Saline + lgG and Saline + CD25 mice at 12 days post-CMV or saline injection $\left({ }^{*} P<0.05\right.$, ANOVA). $N=14$ for the LD-CMV $+C D 25$ group; $N=8$ for the HD-CMV + IgG and HD-CMV + CD25 groups; $N=10$ for other groups.

reduced the frequency of $\mathrm{CD} 25^{+}$Foxp $3^{+}$Tregs in both $\mathrm{CD} 4^{+}$T-cell subset and lymphocyte cell subsets in the spleen at 12 days post-CMV or saline injection (Figures $2 \mathrm{a}$ and $\mathrm{b}$ ). Treg-depleted mice when inoculated with LD-CMV exhibited decreased growth rate compared with other groups without visible jaundice and acholic stools (Figure 1b). Mice infected with $\mathrm{HD}-\mathrm{CMV}$ and injected with isotype-matched $\mathrm{IgG}$ antibody (HD-CMV + IgG) also showed severe growth retardation after virus inoculation (Figure 1b). The following studies were conducted to identify the effects of LD-CMV infection in Treg-depleted mice on bile ducts in this murine model.

\section{LD-CMV Infection Promotes Inflammation at Intrahepatic Bile Ducts in Treg-Depleted Mice}

WT Balb/c mice were infected with LD-CMV or HD-CMV or saline control on day 1 of life, and the hepatobiliary system was examined at 12 days postinfection (dpi). Liver sections were stained with H\&E. Figure 3 shows that LD-CMV infection induced extensive inflammation at intrahepatic bile ducts (Figure 3a3-5), and injury and atresia of intrahepatic bile ducts (Figure 3a6) in Tregs-depleted neonatal mice, without damaging the hepatocytes or blood vessels. HDCMV infection caused inflammatory cell infiltration and fatty degeneration of hepatocytes and injury to biliary epithelium (Figure 3a2). In contrast, there were only few inflammatory cells in the region of the portal tract in the control (salineinjected) mice (Figure 3a1) and in the LD-CMV-infected and isotype-matched $\operatorname{IgG}$ antibody-injected (LD-CMV + $\operatorname{IgG}$ ) mice (data not shown). Anti-cytokeratin 7 or anti-caspase 3 antibody was applied to the liver sections in order to further identify the effect of LD-CMV infection in Treg-depleted mice on the intrahepatic bile ducts and to determine whether apoptosis was induced in LD-CMV-infected and anti-CD25 antibody-treated (LD-CMV $+\mathrm{CD} 25)$ mice. The bile duct epithelia in control mice were intact; however, mice in the LD-CMV + CD25 group had intrahepatic bile duct injuries and atresia (Figure 3b). The expression of active caspase-3 was increased in the livers of mice in the LD-CMV + CD25 group compared with the mice in the control group (Figure 3c).

\section{LD-CMV Exposure Induced Inflammation at the EHBDs Resulting in Partial Luminal Narrowing and Obstruction in Treg-Depleted Mice}

Next, we explored whether the inflammatory responses also impacted EHBDs in mice from the LD-CMV + CD25 group. EHBDs were microdissected at $12 \mathrm{dpi}$ and stained with H\&E. LD-CMV infection in Treg-depleted mice caused inflammatory cells to invade the EHBDs leading to denudement of the epithelial lining, inflammation of subepithelial and intraluminal region and formation of lymphoid follicles (Figure 4a). The EHBD epithelia in control mice appeared normal and contained few inflammatory cells (Figure 4a). Photomicrographs of successive H\&E-stained sections of EHBDs showed partial obstruction due to inflammatory cell infiltration in the intraluminal space and epithelial hyperplasia with luminal narrowing in mice from the LD- 

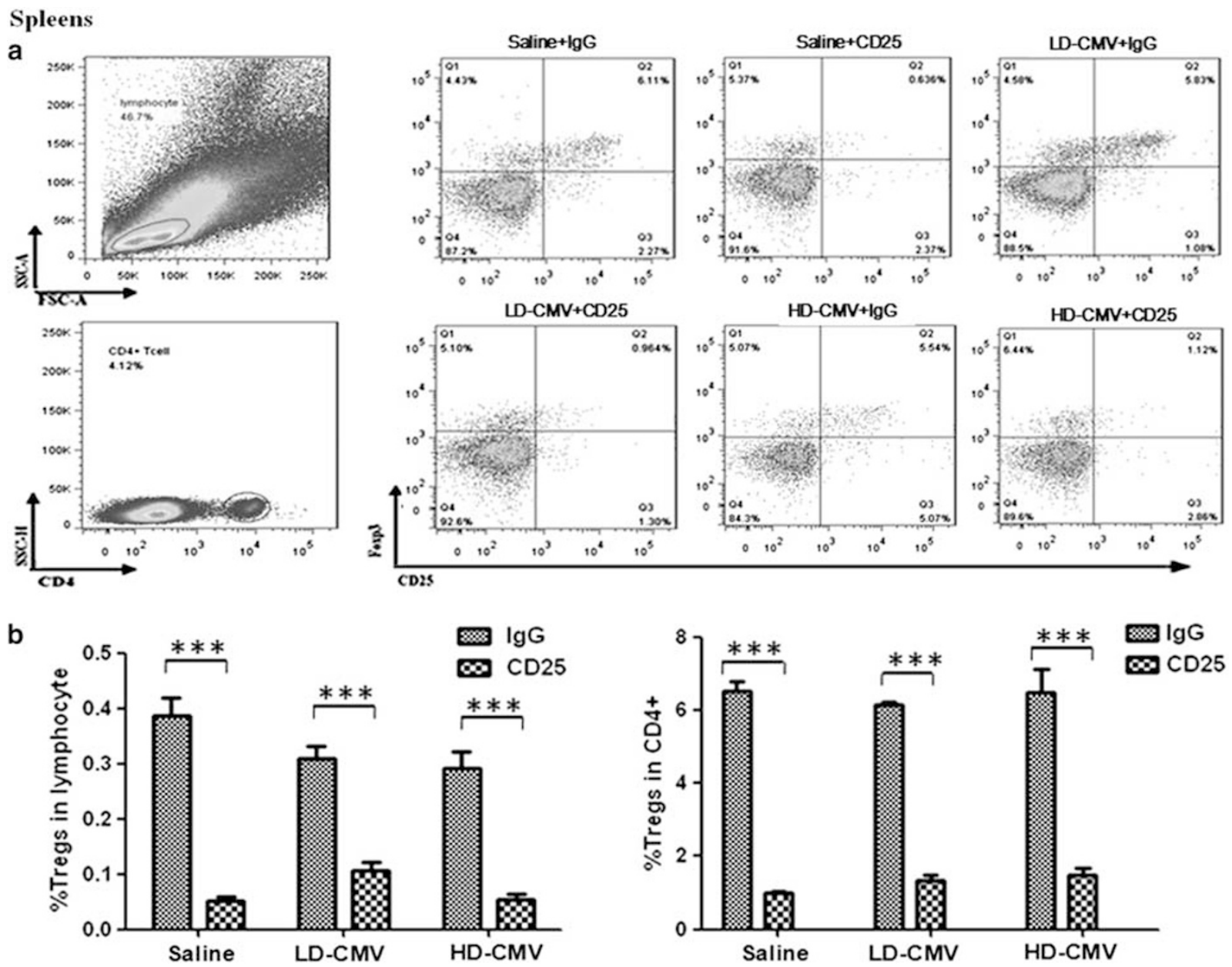

Figure 2 Flow cytometric quantification of $\mathrm{CD}^{+}{ }^{+} \mathrm{CD} 25^{+}$Foxp3 ${ }^{+}$Tregs in MNCs from the spleens of 2-week-old neonatal mice. (a) Left column: boxed dot plots depict size-gated total lymphocytes (top row) and CD4 ${ }^{+}$lymphocytes (bottom row); right column: depicts $\mathrm{CD}^{+}{ }^{+}$lymphocytes expressing $\mathrm{CD} 25$ and the Treg transcription factor Foxp3. (b) The percentage of CD4 ${ }^{+}$lymphocytes co-expressing Foxp $3^{+}$and $\mathrm{CD}_{2} 5^{+}$in CD4 ${ }^{+} \mathrm{T}_{\text {cells }}$ and lymphocytes. Values are expressed as mean \pm s.d. with ${ }^{* * *} P<0.001$ in unpaired $T$-test.

CMV + CD25 group (Figure 4b). Consistent with bile duct injury, serum total bilirubin and direct bilirubin amounts were increased in mice from the LD-CMV + CD25 group, compared with the saline and LD-CMV + IgG groups (Figure 4c).

\section{Antibody-Mediated Depletion of Tregs in Neonatal Mice Increased the Percentage of CD3 and CD8 Lymphocytes in the Liver Following LD-CMV Exposure}

Because Treg depletion can promote inflammation and autoreactivity, the current study evaluated the adaptive immune response by examining T-lymphocyte activation. Hepatic MNCs were isolated at $12 \mathrm{dpi}$, and the frequencies of CD3 and CD8 lymphocytes were analyzed by flow cytometry. We found that injection of anti-CD25 antibody reduced the frequency of Treg numbers in the spleens; however, the numbers of both CD8 and CD3 lymphocytes in mice from the LD-CMV + CD25 group were significantly increased at
$12 \mathrm{dpi}$, compared with the mice from the saline and LDCMV + IgG groups (Figures 5a and b). Notably, the population of CD3 and CD8 lymphocytes in Treg-depleted mice after LD-CMV infection was similar to that in the HD-CMV infected groups.

\section{Autoantibodies to Intrahepatic Biliary Epithelial Proteins are Present in the Serum of Mice from the LD-CMV + CD25 Group}

The presence of humoral autoimmunity in mice from the LD-CMV + CD25 group was also investigated. Autoantibodies exist in many autoimmune diseases and may function primarily as markers of the autoimmune response. Sera from mice in the LD-CMV $+\mathrm{CD} 25$ or saline-injected and isotype-matched IgG antibody-treated (Saline $+\mathrm{IgG}$ ) groups were incubated with murine intrahepatic biliary epithelial cells or liver sections from normal mice and analyzed by immunofluorescence or western immunoblot. Application of 

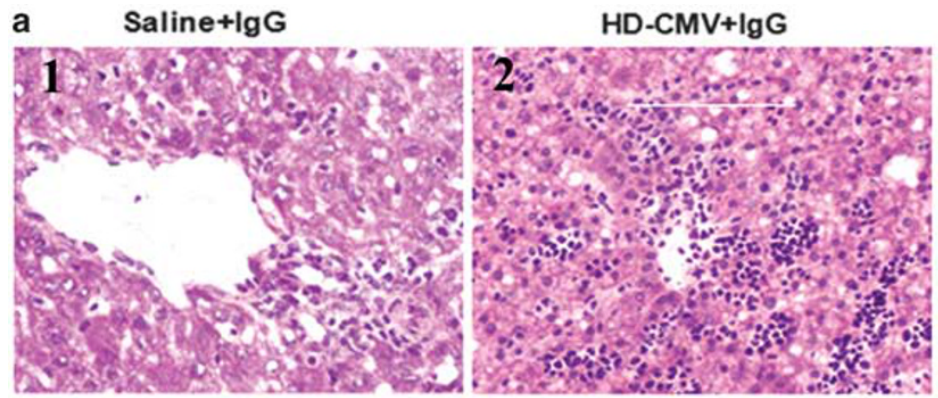

b
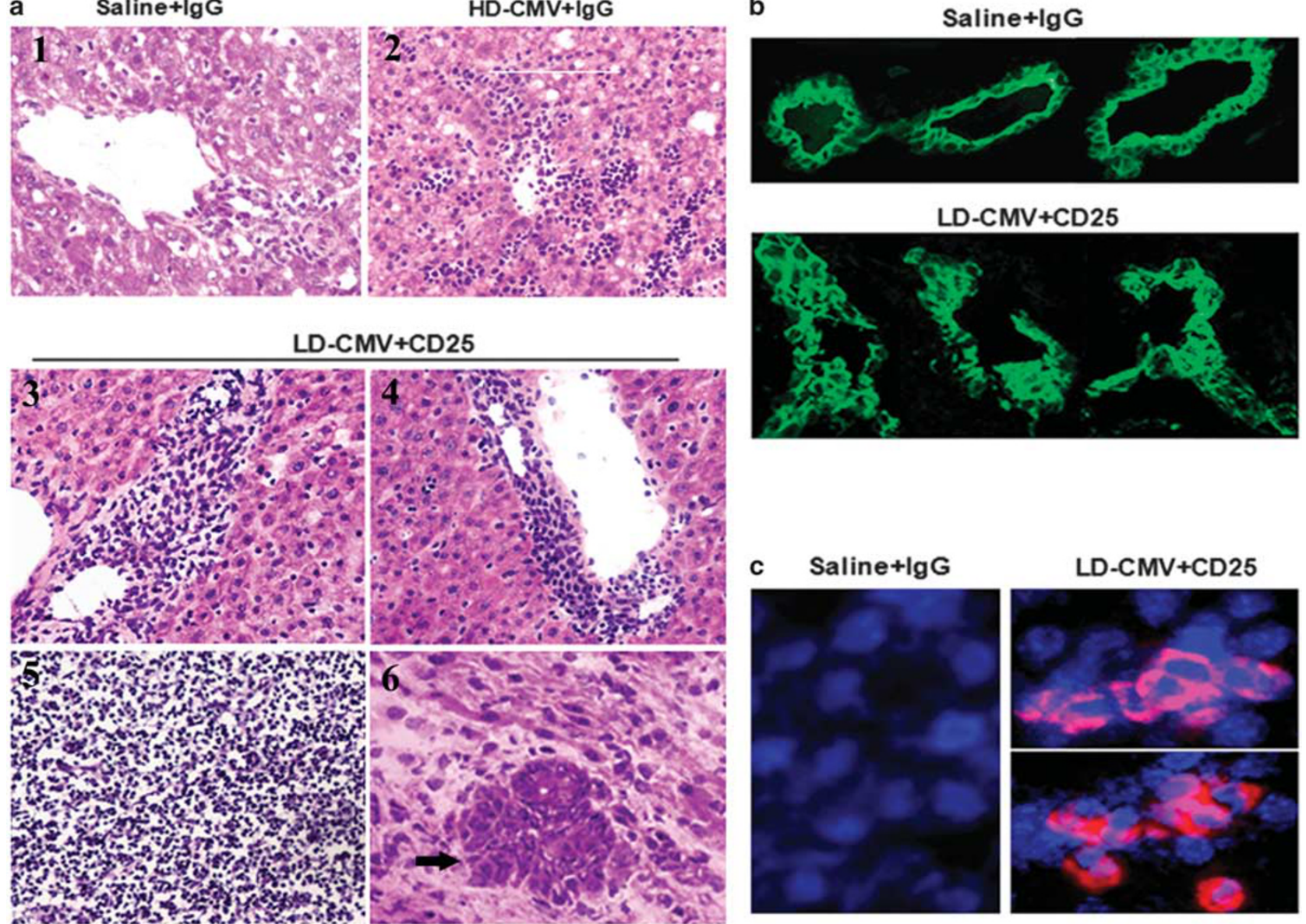

Figure 3 (a) LD-CMV infection induced inflammation at intrahepatic bile ducts in Treg-depleted mice. Liver sections from different groups were stained with H\&E. a3-a5 show extensive inflammation at intrahepatic bile ducts. The black arrow indicates injury and atresia of intrahepatic bile ducts in a6. a1-a5, magnification: $\times 200$; a6, magnification: $\times$ 400. (b and c) Livers were incubated with anti-CK7 (green) or anti-active caspase-3 (red) antibodies. Intrahepatic bile ducts (green) in mice from the LD-CMV + CD25 group appeared to have injuries and atresia (b); active caspase-3-stained cells (red) were detected in LD-CMV + CD25 mice (c). Magnification: $\times 400$.

intrahepatic biliary epithelial cells as a source of cholangiocytes was validated by studying cytokeratin-19 expression (Figure 6c). Autoantibodies were measured in 2-week-old mice owing to the fact that 2-week-old mice are capable of generating substantial amounts of IgG and maternally acquired IgG is less predominant. ${ }^{30}$ Sera from mice in the $\mathrm{LD}-\mathrm{CMV}+\mathrm{CD} 25$ group reacted with the liver section proteins from normal mice (Figure 6a) and intrahepatic biliary epithelial cells (Figure $6 \mathrm{~b}$ ); this was not observed with sera from mice in the Saline + IgG (Figures $6 a$ and $b$ ) or LD-CMV + IgG group (data not shown). The specificity of the autoimmune immunoglobulins in the sera from mice in the Saline + IgG and LD-CMV + CD25 groups was analyzed by western blotting. Studies revealed that sera from both groups contained nonspecific antibodies that were reactive to intrahepatic biliary epithelial proteins of approximately 30 , 40 and $170 \mathrm{KD}$. Importantly, sera from the LD-CMV + CD25 group, but not from the Saline + IgG group, contained specific antibodies that were reactive to multiple intrahepatic biliary epithelial proteins and were strongly reactive to proteins of approximately 45, 58 and $65 \mathrm{KD}$ (boxed bands) (Figure 6d). These 45, 58 and $65 \mathrm{KD}$ proteins in the intrahepatic biliary epithelia represented those autoantigens bound by serum antibodies. Because it has been reported that $\alpha$-enolase is expressed in the bile duct epithelia and generation of anti-enolase antibody has been identified within both the rotavirus-infected BA mice model and in human BA patients, ${ }^{30}$ the sera was incubated with purified enolase and visualized via chemiluminescence. Sera from mice in the LD-CMV + CD25 group reacted strongly with $\alpha$-enolase. To determine whether the serum of the BA mice reacts with other tubular epithelium, tissue sections of the intestine of normal mice were incubated with sera from the LD-CMV + CD25 group, followed by goat anti-mouse IgG secondary antibody, and then counterstained with DAPI. We found that sera from mice in the LD-CMV + CD25 group did not react with the intestinal proteins from normal mice (data not shown). 

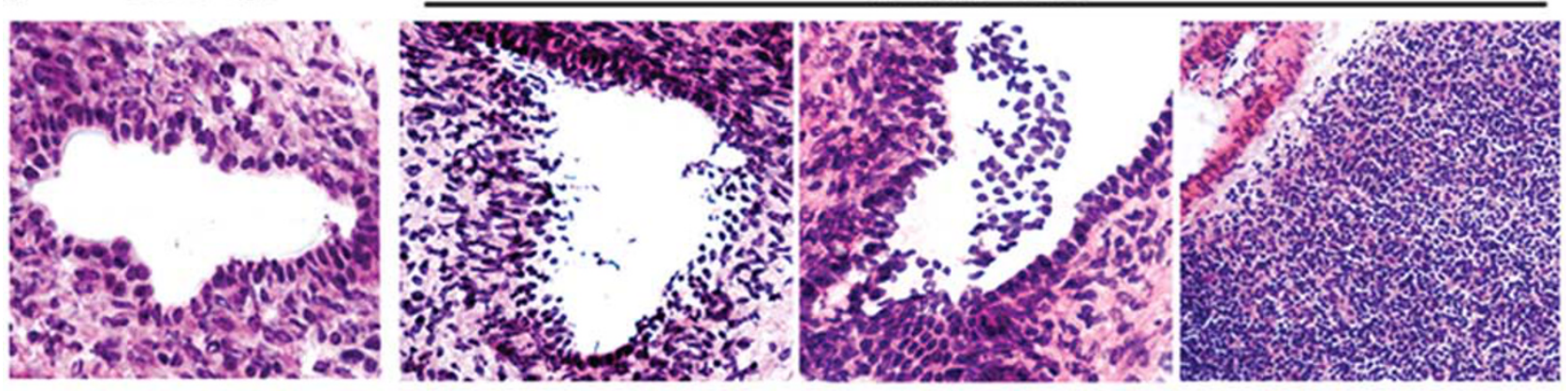

b

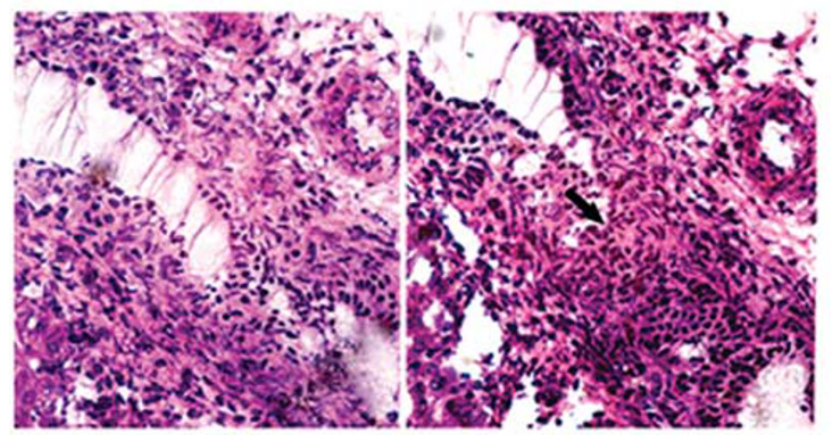

c

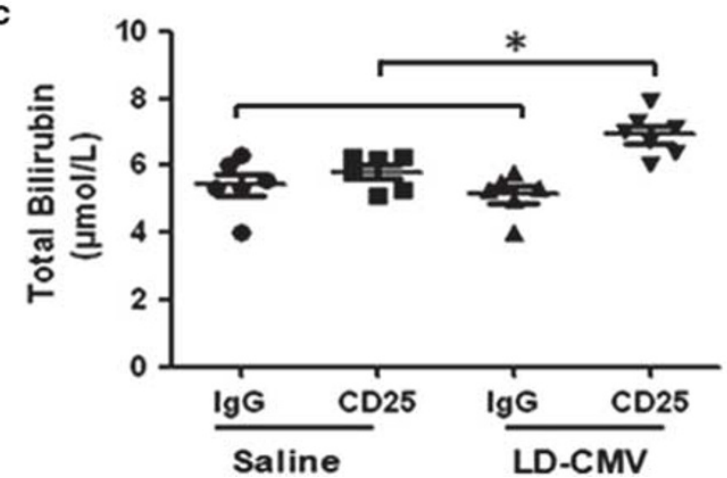

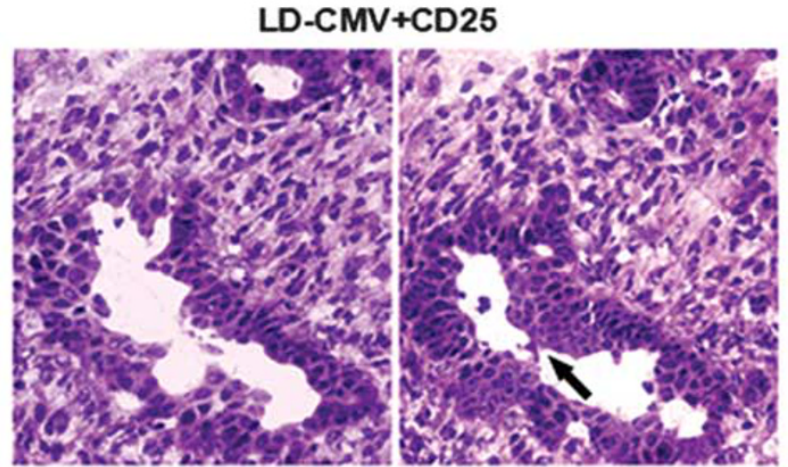

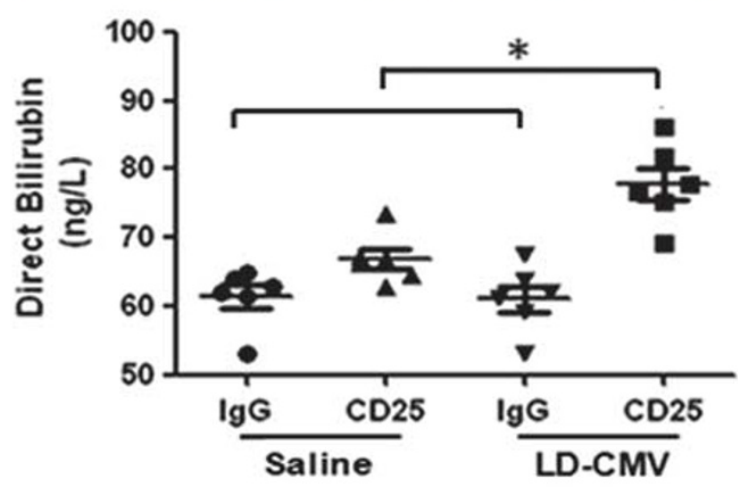

Figure 4 LD-CMV infection induced inflammation in extrahepatic bile ducts resulting in luminal narrowing and partial obstruction in Treg-depleted mice. (a) H\&E staining showed both subepithelial and intraluminal inflammation, invasion of inflammatory cells into the EHBD, along with denudement of the epithelial lining, and lymphoid follicular formation in LD-CMV + CD25 mice. Magnification: $\times 200$. (b) Successive longitudinal sections of extrahepatic bile ducts in mice from the LD-CMV + CD25 group showed partial obstruction by infiltration of inflammatory cells into the intraluminal space (arrows). Cross-sectional views of extrahepatic bile ducts revealed epithelial hyperplasia with luminal narrowing (arrows) in mice from the LD-CMV + CD25 group. Magnification: $\times 200$. (c) The serum concentrations of total bilirubin and direct bilirubin at 12 dpi were determined from ELISA assays. Symbols denote plasma total bilirubin and direct bilirubin concentrations per mouse, horizontal bars indicate mean \pm s.d. Because of the difficulty in obtaining blood sample from pups, not all the subjects were available for ELISA assays. Data were evaluated by one-way ANOVA ( ${ }^{*} P<0.05$ versus Saline + IgG, Saline + CD25 and LD-CMV + IgG groups).

\section{Hepatic Expression of Th1-Related Genes and Th1 Cytokines}

Hepatic mRNA amounts for caspase- 1 , TNF- $\alpha$ and the IFN- $\gamma-$ activated genes STAT-1, IL-17A, IL-4, IL-13 and GATA-3 were quantified using real-time PCR. Caspase-1, Th1-related genes TNF- $\alpha$ and STAT-1 were increased in mice from the LD$\mathrm{CMV}+\mathrm{CD} 25$ group compared with the mice in the control groups (Figure 7a). The amounts of Th2-related genes, IL4, IL13 and Gata-3 mRNA did not differ significantly between different treatment groups (data not shown). IL-17a was not detectable in the livers from mice in the LD-CMV + CD25 or control group. Neither LD-CMV infection nor transient depletion of Tregs alone induced elevated mRNA amounts in the liver. However, LD-CMV infection of Treg-depleted mice activated the Th1-related inflammatory pathway in the liver. A mouse inflammation array was used to further identify the upregulated inflammatory factors in mice from the LD$\mathrm{CMV}+\mathrm{CD} 25$ group. Monocyte chemoattractant protein-1 

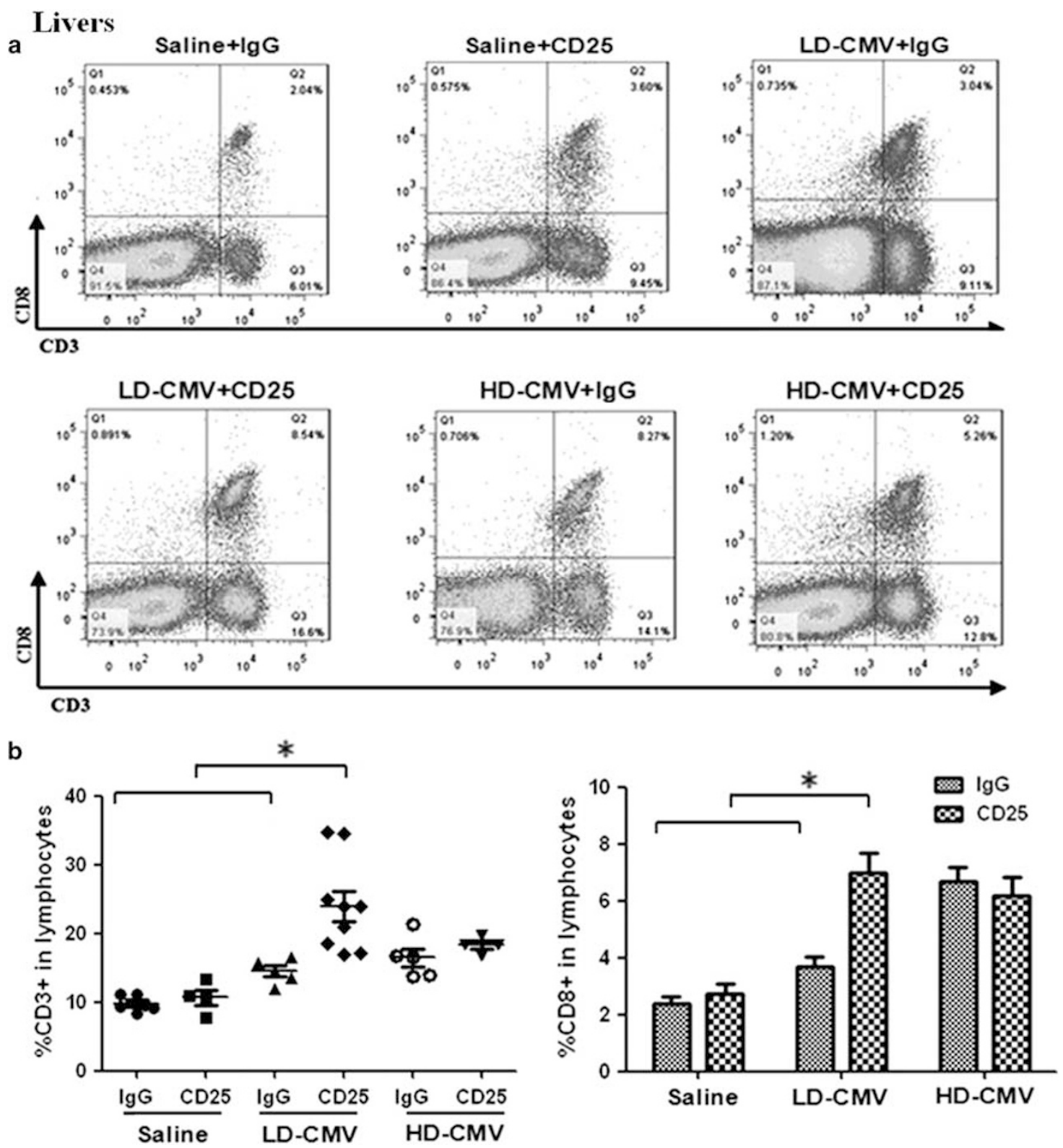

Figure 5 Hepatic MNCs were isolated at $12 \mathrm{dpi}$ and the frequencies of CD3 and CD8 lymphocytes (gated on lymphocytes) were enumerated by flow cytometry. (a) Representative flow cytometry plot of $\mathrm{CD}^{+} \mathrm{MNC}$ expressing $\mathrm{CD} 8$. (b) The percentage of $\mathrm{CD} 3^{+} \mathrm{T}^{+}$cells and $\mathrm{CD} 8^{+} \mathrm{T}$ cells in lymphocytes after CMV or saline injection. Symbols represent the percentage of $\mathrm{CD}^{+}{ }^{+}$cells in MNC per mouse, the horizontal bars indicate mean \pm s.d. Values of $\mathrm{CD}^{+} \mathrm{T}$ cells in lymphocytes are displayed as mean \pm s.d. Due to the limited amount of fresh liver samples from pups, not all the subjects were available for flow cytometry. Data were evaluated by one-way ANOVA ( ${ }^{*} P<0.05$ versus Saline $+\lg G$, Saline + CD25 and LD-CMV + lgG groups).

and macrophage colony-stimulating factor were increased in mice from the LD-CMV + CD25 group when compared with the mice in the Saline + IgG group. Th1-related cytokines, TNF- $\alpha$, lymphotactin, interleukin-12p40 and macrophage inflammatory protein $-1 \gamma$ were elevated the most in mice from the LD-CMV $+\mathrm{CD} 25$ group (Figures $7 \mathrm{~b}$ and $\mathrm{c}$ ). This was consistent with the elevated hepatic Th1-related gene mRNA amounts identified earlier in this study. There were no significant differences in the cytokines of Th2 or Th17 pathways in the microarray analysis between the mice from the LD-CMV + CD25 group and other groups.

\section{Immunohistochemical Analysis for $\alpha$-SMA and CMV Antigens in Livers}

To identify the fibrotic changes in the livers of LD-CMV + CD25 mice, we evaluated $\alpha$-SMA, a marker protein of hepatic fibrosis, for liver samples harvested at $12 \mathrm{dpi}$. Although LD-CMV infection in Treg-depleted mice induced extensive inflammation at bile ducts, $\alpha$-SMA was not detected in liver samples of $\mathrm{LD}-\mathrm{CMV}+\mathrm{CD} 25$ mice (Figure $8 \mathrm{a}$ ). We conclude that our mouse model is still in the stage of liver inflammation, and it takes a longer time to transfer to the stage of liver fibrosis. 
a
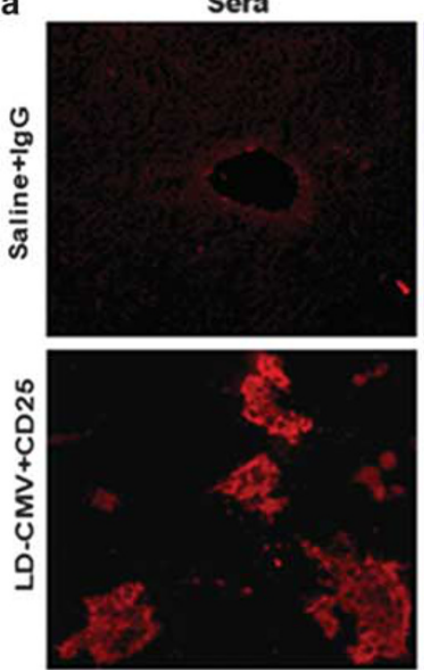

b
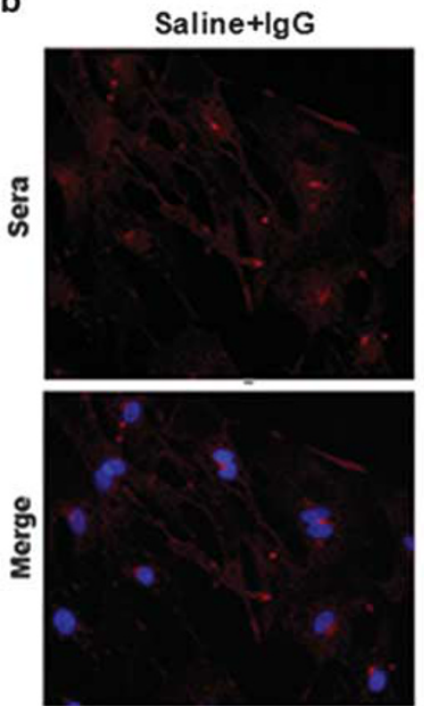

DAPI
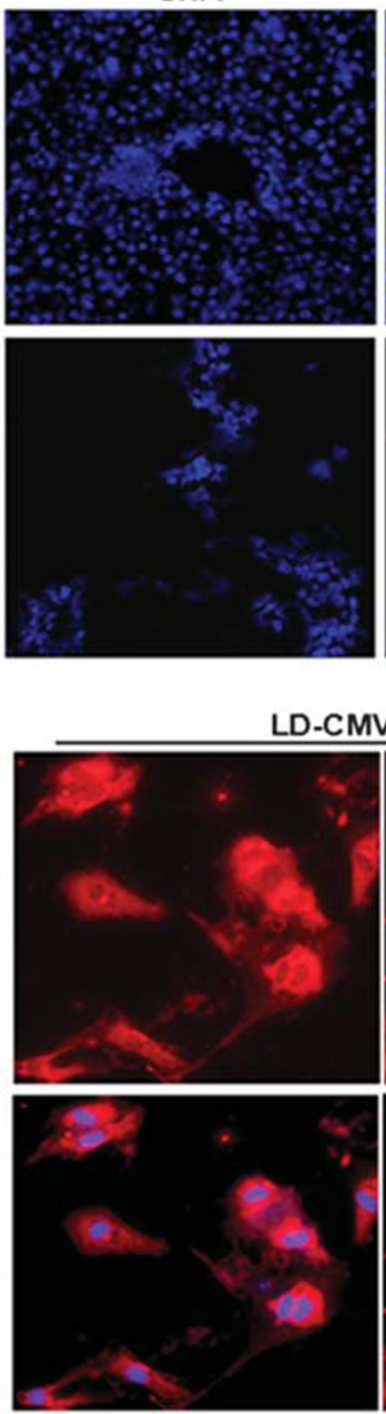

Merge
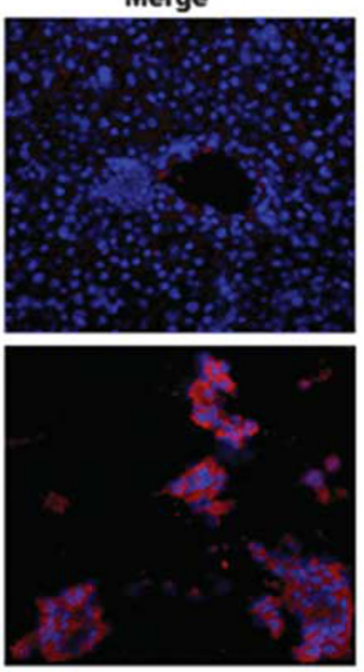

D-CMV+CD25

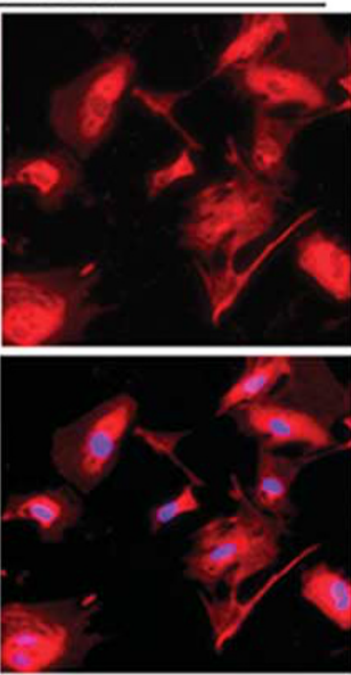

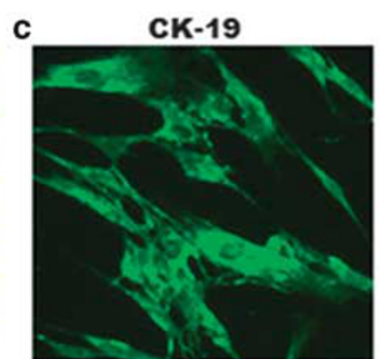

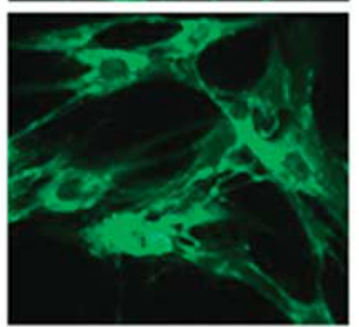

d BDE

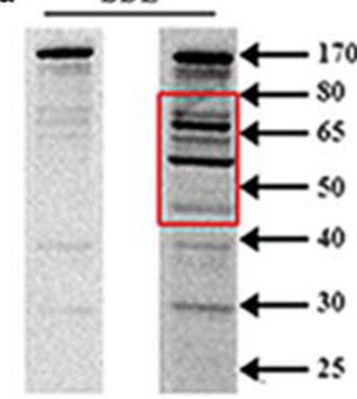

Saline+lgG LD.CMV+CD25

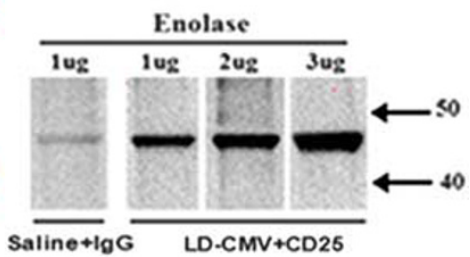

Figure 6 Serum antibodies reactive to bile duct epithelial proteins are evident in 2-week-old LD-CMV-infected Treg-depleted mice. (a) Liver sections from normal mice were incubated with sera from mice in Saline + IgG or LD-CMV + CD25 mice, followed by goat anti-mouse IgG secondary antibody (Red) and then counterstained with DAPI (blue). (b) Normal murine intrahepatic biliary epithelial cells were also incubated with sera from mice in the Saline + IgG or LD-CMV + CD25 group, followed by goat anti-mouse lgG secondary antibody (Red) and then counterstained with DAPI (blue) to detect cellular nuclei. Sera from mice in the LD-CMV + CD25 group had detectable lgG immune antibodies that targeted intrahepatic biliary epithelial cells. Magnification: $\times 200$. (c) Normal murine intrahepatic biliary epithelial cells were incubated with anti-cytokeratin 19 antibodies (green) and were used to confirm bile duct epithelial nature. Magnification: $\times 200$. (d) Intrahepatic biliary epithelial cell homogenates were separated by gel electrophoresis, blotted onto nitrocellulose paper and incubated with sera from mice in the Saline + IgG or LD-CMV + CD25 group. Sera from the LD-CMV + CD25 group contained specific antibodies reactive to multiple intrahepatic biliary epithelial proteins and were strongly reactive to proteins of approximately 45,58 and $65 \mathrm{KD}$ (boxed bands). Purified enolase was also incubated with sera from different groups, and sera from mice in the LD-CMV + CD25 group showed strong reactivity to $\alpha$-enolase (48 KD).

To determine whether CMV antigens were detected in the liver tissues or biliary tree of LD-CMV infected mice, immunohistochemical analysis for liver samples harvested at 12 dpi using a rabbit anti-CMV PP65 IgG antibody was performed. We found that CMV PP65 was detected in both hepatocytes and biliary epithelia (Figure $8 \mathrm{~b}$ ) of LD-CMV + CD25 mice. The distribution of viral protein suggested that
CMV had tropism for the hepatobiliary system and initiated bile duct damages.

\section{DISCUSSION}

It has been proposed that BA is the result of a 'multihit' pathological process, in which a viral insult to the biliary epithelium leads to altered antigens on the surface of the bile 

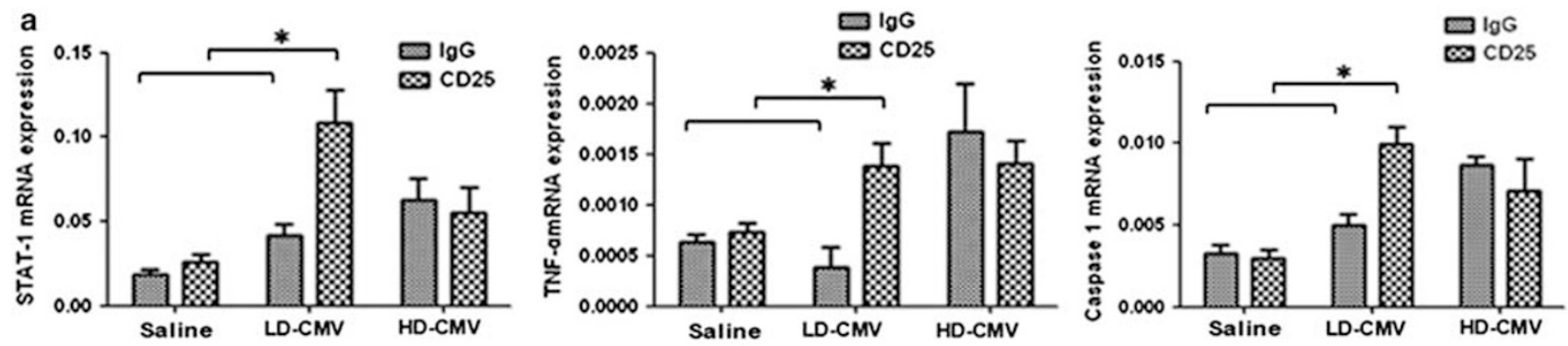

b

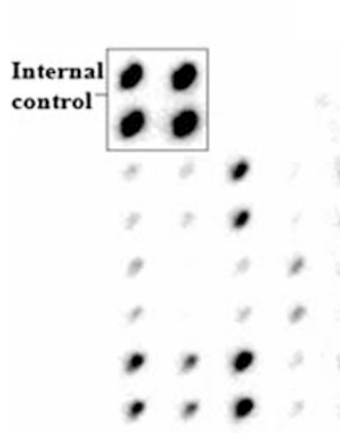

Saline+lgG
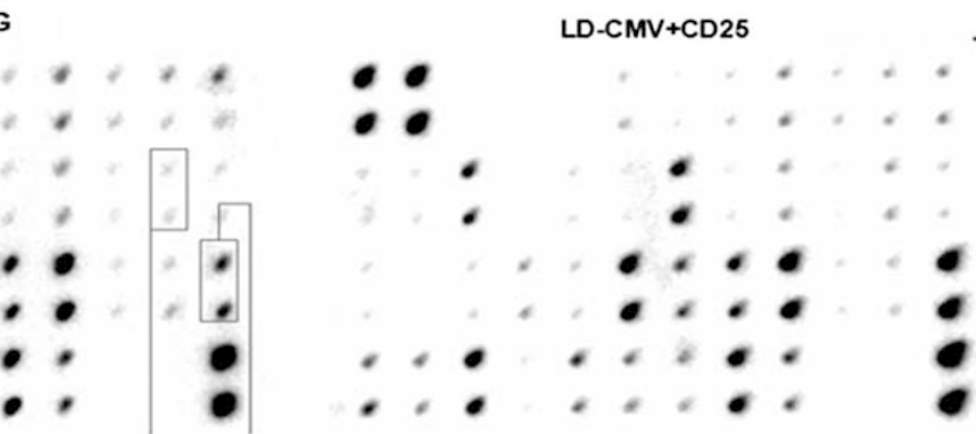

IL-12p40 MIIP-1 $\gamma$

C

Mouse inflammatory factors elevated in LD-CMV+CD25 group

\begin{tabular}{lcc}
\hline & Mouse inflammatory factors & Fold increase \\
\hline MIP-1 $1 \gamma$ & macrophage inflammatory protein $-1 \gamma$ & 4.5 \\
IL-12p40 & Interleukin-12p40 & 4.3 \\
TNF- $\alpha$ & tumor necrosis factor- $\alpha$ & 2.3 \\
MCP-1 & Monocyte chemoattractant protein-1 & 1.7 \\
Lymphotactin & Lymphotactin & 1.6 \\
MCSF & Macrophage Colony-Stimulating Factor & 1.6 \\
\hline
\end{tabular}

Figure 7 Increased hepatic expression for Th1 genes and Th1 cytokines in mice from the LD-CMV + CD25 group. (a) mRNA expression for caspases-1, TNF- $\alpha$ and IFN- $\gamma$-activated genes STAT-1 in the livers harvested from mice at $12 \mathrm{dpi}$ after CMV or saline injection. Relative mRNA amounts were determined by real-time PCR and are expressed after normalization to GAPDH. Values of caspase-1, STAT- 1 and TNF- $\alpha$ expression are displayed as mean \pm s.d. ( ${ }^{*} P<0.05$ versus Saline + IgG, Saline + CD25 and LD-CMV + IgG groups). (b) Mouse inflammation array was used to determine the differences in inflammatory pathways between mice in the LD-CMV + CD25 and Saline + IgG groups. Autoradiographs of the arrays were scanned to determine the density of the protein in the array. (c) Values from scans were adjusted based on the intensity of control spots on the filter corners, and significance was determined if the intensity increased above 1.5 -fold from baseline. Representative array from three experimental repeats.

duct epithelia. This stimulates autoimmune response against the bile ducts, resulting in biliary injury and cirrhosis. ${ }^{32}$ For many years, CMV has been indicated as a possible etiological agent in BA. A study from Sweden showed that CMV DNA was present in $50 \%$ of BA cases. ${ }^{33}$ Mack et al ${ }^{19,30}$ found that $56 \%$ of BA patients had significant increases in liver T-cell numbers in response to $\mathrm{CMV}^{19}$ Both of these findings indicate that nearly half of BA patients had previous CMV infection. Furthermore, BA shares features with several autoimmune diseases, such as being triggered by a viral infection and the presence of serum autoantibodies and aberrant MHC expression in the bile duct epithelium. ${ }^{2}$ Evidence for humoral autoimmunity in BA also exists. Vasiliauskas et $a l^{34}$ reported that 10 of the 11 patients with BA were positive for serum $\operatorname{IgG}$ and $\operatorname{IgM}$ antineutrophil cytoplasmic antibodies. ${ }^{2}$ Mack et al identified serum autoantibodies reactive to multiple proteins, including $\alpha$-enolase, present in the bile duct epithelia of BA patients, but not in samples from control patients. ${ }^{30}$ Consequently, it has been proposed that tissue injury in patients with BA may represent an autoimmune-mediated process. One potential mechanism to explain the abnormal autoimmune response is loss of functional Tregs, which could result in an exaggerated inflammatory and autoimmune-mediated response following a recent virus infection. Recent studies have identified lower numbers of Tregs in BA patients compared with controls. ${ }^{19}$ This is similar to the situation in many autoimmune diseases and suggests that impaired ability to inhibit inflammation and autoreactive immune responses following a perinatal CMV infection might allow bile duct injury to progress further. 
a

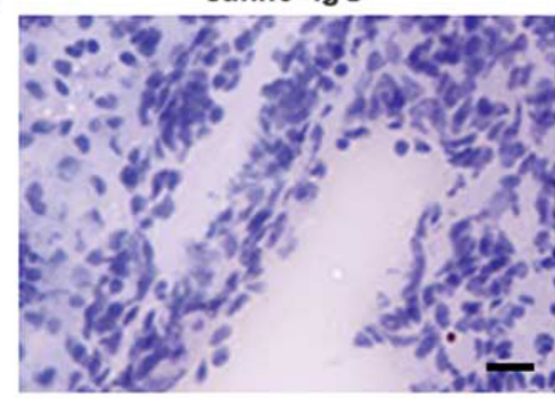

LD-CMV+CD25

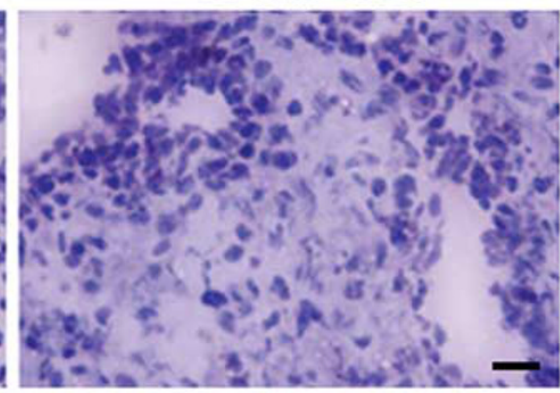

b

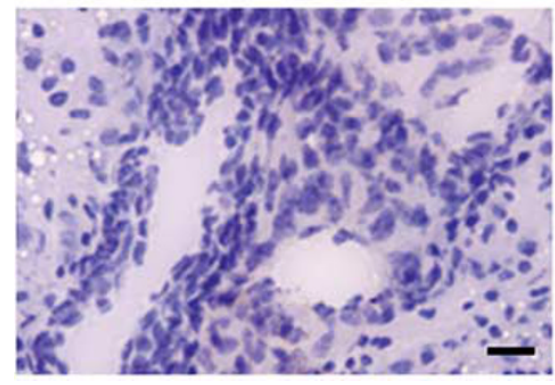

LD-CMV+CD25

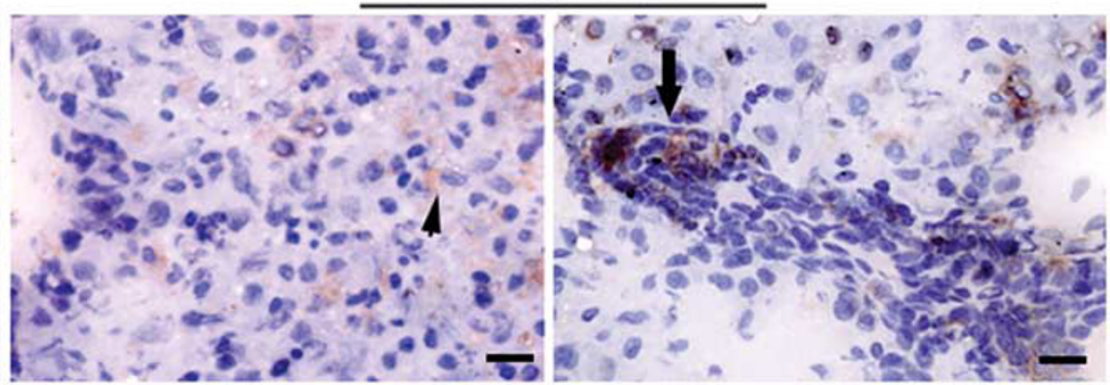

Figure 8 Immunohistochemical analysis for $\alpha$-SMA and CMV PP65 in liver samples. (a) Immunohistochemical analysis for $\alpha$-SMA was performed. $\alpha$-SMA was not detected in liver samples of LD-CMV + CD25 mice. Magnification: $\times 400$. (b) Immunohistochemical analysis for liver samples harvested at 12 dpi using a rabbit anti-CMV PP65 lgG antibody was performed. CMV PP65 was detected in both hepatocytes (black arrowhead) and biliary epithelia (black arrow) of LD-CMV + CD25 mice. Magnification: $\times 400$.

In the current study, a Treg-depleted mouse was infected with LD-CMV as a model to study human BA and to determine whether decreased Treg percentages and/or LD-CMV infection could induce immune responses to result in further bile duct injury. The generation of bile duct-specific cellular and humoral autoimmune responses was demonstrated in this model. This was consistent with the detection of autoantibodies in BA and further supports the virally induced, autoimmune-mediated theory regarding the pathogenesis and progression of BA. Specifically, evidence for humoral autoimmunity was obtained by demonstrating the presence of serum autoantibodies reactive to intrahepatic bile duct epithelia. Western immunoblot analysis identified the presence of sera autoantibodies against 45, 58 and $65 \mathrm{KD}$ intrahepatic biliary epithelial proteins. Identification of these specific proteins in these three bands is still under investigation and is not addressed in this study, though anti- $\alpha$ enolase autoantibodies in mice from the LD-CMV + CD25 group were detected. $\alpha$-Enolase is an enzyme involved in glycolysis and is ubiquitously expressed in a variety of cells, including biliary epithelial cells and hepatocytes. Anti- $\alpha$ enolase antibody is not only detected in human BA but also in many autoimmune diseases, thus our finding of antienolase antibody in this animal model suggests that this antibody is a potential biomarker of the humoral autoimmune response. ${ }^{30,35}$ This implies that anti-enolase autoantibodies produced following LD-CMV infection may have a role in biliary injury. Cellular autoimmunity was deter- mined by observing the status of T-lymphocyte activation. The frequencies of CD8 and CD3 lymphocytes were increased after LD-CMV infection in Treg-depleted mice, suggesting that a strong cellular immunity was induced in this murine BA model. To determine whether T-cells react specifically with bile duct epithelium and not with residual CMV antigens that may be present in the bile ducts of the infected mice, adoptive transfer experiments of CD4 or CD8 cells from the LD-CMV anti-CD25 mice into SCID mice need to be conducted in future studies. Upregulated Th1-related genes (TNF- $\alpha$ ), IFN- $\gamma$-activated genes (STAT-1) and Th1 cytokines (TNF- $\alpha$, lymphotactin, IL-12p40 and MIP $-1 \gamma$ ) were observed in the murine BA model. TNF- $\alpha$ is a pleiotropic cytokine that modulates cell hyperplasia or apoptosis in different cells lineages. IFN- $\gamma$ and TNF- $\alpha$ have been reported to cause the activation of caspases and to decrease the viability of cholangiocytes in a BA animal study. ${ }^{3}$ It has also been demonstrated that Th1 cells can maintain and/or amplify an ongoing Th1 response via the release of chemokines, such as MIP $-1 \gamma$, lymphotactin and IL-12p40. ${ }^{36}$ MIP- $1 \gamma$ can recruit $\mathrm{CD}^{+}{ }^{+}$cytotoxic $\mathrm{T}$ cells to inflamed or infected tissues, and overexpression of IL-12p40 has been reported in Th1-mediated autoimmune and chronic inflammatory diseases. ${ }^{37}$ Therefore the predominant hepatic expression for Th1-related genes and cytokines raised the possibility that the Th1 response resulted in the inflammatory and autoimmune-mediated bile duct injury of mice from the LD-CMV + CD25 group. 
One of the highlights in this study compared with the high-dose (RRV) mouse model, which is a very known animal model of BA, is the use of low-dose virus, as no obvious signs of viral infection are usually detected in BA patients and neonatal BA patients with obvious signs of viral infections (high dose) undergo treatment. The use of low-dose virus can better simulate the experience of BA patients. Importantly, based on studies showing that, even after successful removal of obstructed EHBDs via portoenterostomy and the restoration of adequate bile flow, $80 \%$ of patients with BA will ultimately require liver transplantation owing to the progressive nature of this disease, ${ }^{1,5}$ we propose that $\mathrm{CMV}$-induced autoimmune-mediated and inflammatory response may account for the progressive biliary injury, cirrhosis and eventual requirement for liver transplantation observed in BA patients. Although LD-CMV infection generated immune activation and specific bile duct injury in Treg-depleted neonatal mice, accompanied with injury to and atresia of intrahepatic bile ducts and partial obstruction of the EHBDs, they did not induce the complete atresia phenotype of duct obstruction. It is tempting to speculate that the development of the atresia phenotype requires the synergy of other effector cells to obstruct the duct lumen.

In summary, our findings provide evidence that the decreased inhibition of aberrantly activated hepatic T-lymphocytes and autoantibodies, owing to a lack of Tregs, leads to exaggerated and progressive intrahepatic and EHBD injury. Importantly, as both previous CMV infection and Treg deficiency exist in the majority of BA patients, we suggest that future research should be focused on the role of Tregs and autoimmunity in human BA patients and possible interventional strategies.

\section{ACKNOWLEDGMENTS}

This work was supported by grants from the National Natural Science Foundation of China (81200457), Shanghai Key Laboratory of Pediatric Gastroenterology and Nutrition (14DZ2272400), Science and Technology Funding in Shanghai Jiao Tong University School of Medicine (12XJ30066) and Funding of Shanghai municipal bureau of health (2013Y173). The funders had no role in study design, data collection and analysis, decision to publish or preparation of the manuscript

\section{AUTHOR CONTRIBUTIONS}

The experiments were conceived and designed by JW, YTX, WC and ZHY. The experiments were performed by JW, WHP, YZ and XLZ. The data were analyzed by JW, WBG, YWC, KJZ and YW. Contributions of reagents/materials/analysis tools were made by BSS and XHZ. The manuscript was written by JW, YTX and WC

\section{DISCLOSURE/CONFLICT OF INTEREST}

The authors declare no conflict of interest.

1. Mack CL, Tucker RM, Lu BR, et al. Cellular and humoral autoimmunity directed at bile duct epithelia in murine biliary atresia. Hepatology 2006;44:1231-1239.
2. Sokol RJ, Mack C, Narkewicz MR, et al. Pathogenesis and outcome of biliary atresia: current concepts. J Pediatr Gastroenterol Nutr 2003; 37:4-21.

3. Erickson N, Mohanty SK, Shivakumar P, et al. Temporal-spatial activation of apoptosis and epithelial injury in murine experimental biliary atresia. Hepatology 2008;47:1567-1577.

4. Shivakumar P, Sabla GE, Whitington $P$, et al. Neonatal NK cells target the mouse duct epithelium via Nkg2d and drive tissuespecific injury in experimental biliary atresia. J Clin Invest 2009;119: 2281-2290.

5. Lykavieris $P$, Chardot $C$, Sokhn $M$, et al. Outcome in adulthood of biliary atresia: a study of 63 patients who survived for over 20 years with their native liver. Hepatology 2005;41:366-371.

6. Pape L, Olsson K, Petersen C, et al. Prognostic value of computerized quantification of liver fibrosis in children with biliary atresia. Liver Transplant 2009;15:876-882.

7. Weerasooriya VS, White FV, Shepherd RW. Hepatic fibrosis and survival in biliary atresia. J Pediatr 2004;144:123-125.

8. Miethke AG, Saxena V, Shivakumar P, et al. Post-natal paucity of regulatory $T$ cells and control of NK cell activation in experimental biliary atresia. J Hepatol 2010;52:718-726.

9. Mack CL, Falta MT, Sullivan AK, et al. Oligoclonal expansions of CD4 + and CD8 + T-cells in the target organ of patients with biliary atresia. Gastroenterology 2007;133:278-287.

10. Selmi C, Vergani D, Mieli-Vergani G. Viruses and autoantibodies in biliary atresia. Gastroenterology 2010;139:1461-1464.

11. Shivakumar P, Sabla G, Mohanty S, et al. Effector role of neonatal hepatic CD8 + lymphocytes in epithelial injury and autoimmunity in experimental biliary atresia. Gastroenterology 2007;133:268-277.

12. Mack CL, Tucker RM, Sokol RJ, et al. Biliary atresia is associated with $\mathrm{CD} 4+$ Th1 cell-mediated portal tract inflammation. Pediatr Res 2004;56:79-87.

13. Mack CL, Tucker RM, Sokol RJ, et al. Armed CD4 + Th1 effector cells and activated macrophages participate in bile duct injury in murine biliary atresia. Clin Immunol 2005;115:200-209.

14. Hertel PM, Crawford SE, Finegold MJ, et al. Osteopontin upregulation in rotavirus-induced murine biliary atresia requires replicating virus but is not necessary for development of biliary atresia. Virology 2011;417:281-292.

15. Oku T, Maeda M, Waga $\mathrm{E}$, et al. Cytomegalovirus cholangitis and pancreatitis in an immunocompetent patient. J Gastroenterol 2005:40:987-992.

16. Evans PC, Coleman N, Wreghitt TG, et al. Cytomegalovirus infection of bile duct epithelial cells, hepatic artery and portal venous endothelium in relation to chronic rejection of liver grafts. J Hepatol 1999:31:913-920.

17. Wang W, Zheng S, Shong Z, et al. Development of a guinea pig model of perinatal cytomegalovirus-induced hepatobiliary injury. Fetal Pediatr Pathol 2011;30:301-311.

18. $\mathrm{Xu} \mathrm{Y,} \mathrm{Yu} \mathrm{J,} \mathrm{Zhang} R$, et al. The perinatal infection of cytomegalovirus is an important etiology for biliary atresia in China. Clin Pediatr (Phila) 2012:51:109-113.

19. Brindley SM, Lanham AM, Karrer FM, et al. Cytomegalovirus-specific T-cell reactivity in biliary atresia at the time of diagnosis is associated with deficits in regulatory T cells. Hepatology 2012;55:1130-1138.

20. Soomro GB, Abbas Z, Hassan M, et al. Is there any association of extra hepatic biliary atresia with cytomegalovirus or other infections? J Pak Med Assoc 2011;61:281-283.

21. Shen C, Zheng S, Wang W, et al. Relationship between prognosis of biliary atresia and infection of cytomegalovirus. World J Pediatr 2008;4:123-126.

22. Fontenot JD, Gavin MA, Rudensky AY. Foxp3 programs the development and function of CD4 $+\mathrm{CD} 25+$ regulatory $\mathrm{T}$ cells. Nat Immunol 2003;4:330-336.

23. Kim JM, Rasmussen JP, Rudensky AY. Regulatory $\mathrm{T}$ cells prevent catastrophic autoimmunity throughout the lifespan of mice. Nat Immunol 2007:8:191-197.

24. Tucker RM, Feldman AG, Fenner EK, et al. Regulatory T cells inhibit Th1 cell-mediated bile duct injury in murine biliary atresia. J Hepatol 2013;59:790-796.

25. Lages CS, Simmons J, Chougnet CA, et al. Regulatory T cells control the $\mathrm{CD} 8$ adaptive immune response at the time of ductal obstruction in experimental biliary atresia. Hepatology 2012;56:219-227. 
26. McHugh RS, Shevach EM. Cutting edge: depletion of CD4 + CD25 + regulatory $T$ cells is necessary, but not sufficient, for induction of organ-specific autoimmune disease. J Immunol 2002;168: 5979-5983.

27. Gao L, Qian S, Zeng L, et al. An animal model of human cytomegalovirus infection. Transplant Proc 2007;39:3438-3443.

28. Dunkel EC, de Freitas $\mathrm{D}$, Scheer $\mathrm{Dl}$, et al. A rabbit model for human cytomegalovirus-induced chorioretinal disease. J Infect Dis 1993;168: 336-344.

29. Meng H, Sun D, Wang J. [An experimental study of rat infected with human cytomegalovirus AD169 strain]. Zhonghua Shi Yan He Lin Chuang Bing Du Xue Za Zhi 2000;14:271-273, 302.

30. Lu BR, Brindley SM, Tucker RM, et al. alpha-enolase autoantibodies cross-reactive to viral proteins in a mouse model of biliary atresia. Gastroenterology 2010;139:1753-1761.

31. Terrier B, Degand N, Guilpain P, et al. Alpha-enolase: a target of antibodies in infectious and autoimmune diseases. Autoimmun Rev 2007;6:176-182.
32. Schreiber RA, Kleinman RE. Genetics, immunology, and biliary atresia: an opening or a diversion? J Pediatr Gastroenterol Nutr 1993;16: 111-113.

33. Fischler B, Ehrnst A, Forsgren $M$, et al. The viral association of neonatal cholestasis in Sweden: a possible link between cytomegalovirus infection and extrahepatic biliary atresia. J Pediatr Gastroenterol Nutr 1998;27:57-64.

34. Vasiliauskas E, Targan S, Cobb L, et al. Biliary atresia-an autoimmune disorder? Hepatology 1995;22:87.

35. Akisawa N, Maeda T, Iwasaki S, et al. Identification of an autoantibody against alpha-enolase in primary biliary cirrhosis. J Hepatol 1997;26: 845-851.

36. Muller K, Bischof S, Sommer F, et al. Differential production of macrophage inflammatory protein 1gamma (MIP-1gamma), lymphotactin, and MIP-2 by CD4 $(+)$ Th subsets polarized in vitro and in vivo. Infect Immun 2003;71:6178-6183.

37. Maurer $M$, von Stebut E. Macrophage inflammatory protein-1. Int J Biochem Cell Biol 2004;36:1882-1886. 